\title{
Lifesaving Vertebral Artery Stenting in a Child With Takayasu Arteritis
}

\author{
Afshin Borhani Haghighi ${ }^{1}$; Golnoush Sadat Mahmoudi Nezhad ${ }^{2}$; Hamid Amoozgar ${ }^{3,{ }^{*}}$ \\ ${ }^{1}$ Neurology Department, Shiraz University of Medical Sciences, Shiraz, IR Iran \\ ${ }^{2}$ Student Research Committee, Shiraz University of Medical Sciences, Shiraz, IR Iran \\ ${ }^{3}$ Cardiac and Neonatology Research Center, Shiraz University of Medical Sciences, Shiraz, IR Iran \\ *Corresponding author: Hamid Amoozgar, Cardiac and Neonatology Research Center, Shiraz University of Medical Sciences, P. O. Box: 71937-11351, Shiraz, IR Iran. Tel: +98-9173111877, \\ E-mail: amozgah@sums.ac.ir
}

Received: February 6, 2015; Revised: February 25, 2015; Accepted: March 11, 2015

Keywords: Stenting; Takayasu Arteritis; Vertebral Artery

\section{Dear Editor,}

Takayasu arteritis (TA) is a rare granulomatous panarteritis that involves large vessels predominantly the thoracoabdominal aorta and its branches (1). Angiography, particularly subtraction angiography is the procedure of choice for diagnosis of patients with TA and provides an appropriate guide for endovascular procedure $(2,3)$.

A ten-year-old Afghan girl was referred to the pediatric cardiology ward of Namazee Hospital, Shiraz, Iran due to a history of fever, vascular claudication, and easy fatigability in both lower extremities. In physical examination, pulseless upper extremities and carotid artery bruit were detected. One year prior to this admission, the patient was labeled as a case of Henoch-Schonlein purpura due to her first presentation with rash and fever. In spite of this management, erythrocyte sedimentation rate and $C$ reactive protein levels had not returned to the normal range. Color Doppler sonography of both upper extremities showed the significant thickening of intima and media, diffuse lumen narrowing of both subclavian arteries, subclavian and axillary arteritis. Bringing together all the aforementioned findings, the patient's impression was changed to the TA; therefore, prednisolone and infliximab was started. The patient was followed at the outpatient clinic. Four months later, she was admitted in the hospital due to decreased level of consciousness following left sided paralysis in both upper and lower extremities and status epilepticus. In her physical exam, motor power of the left upper and lower extremities was 1/5. The brain computerized tomography showed a small size intra-cerebral hemorrhage in the frontal lobe. Brain magnetic

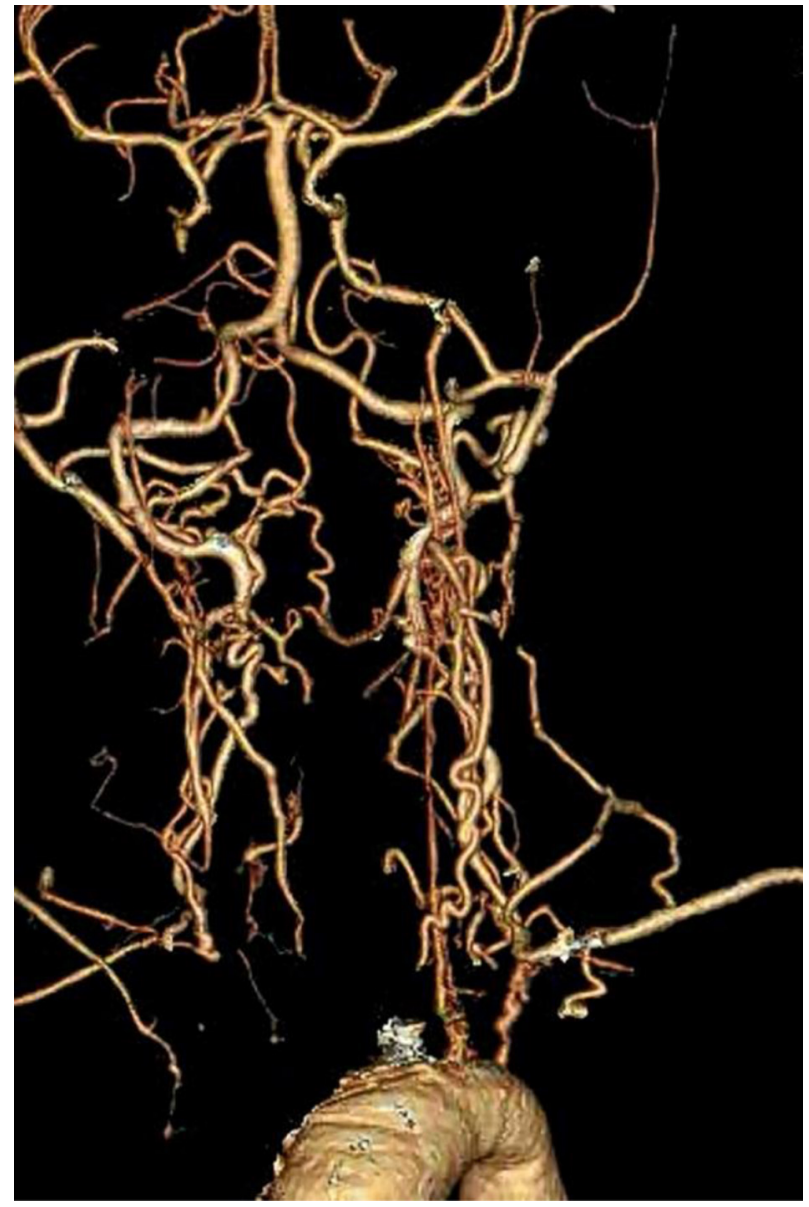

Figure 1. Multislice Computerize Tomography Shows Stenosis of Both Carotids And Subclavian Arteries

Copyright (C) 2015, Growth \& Development Research Center. This is an open-access article distributed under the terms of the Creative Commons Attribution-NonCommercial 4.0 International License (http://creativecommons.org/licenses/by-nc/4.0/) which permits copy and redistribute the material just in noncommercial usages, provided the original work is properly cited. 

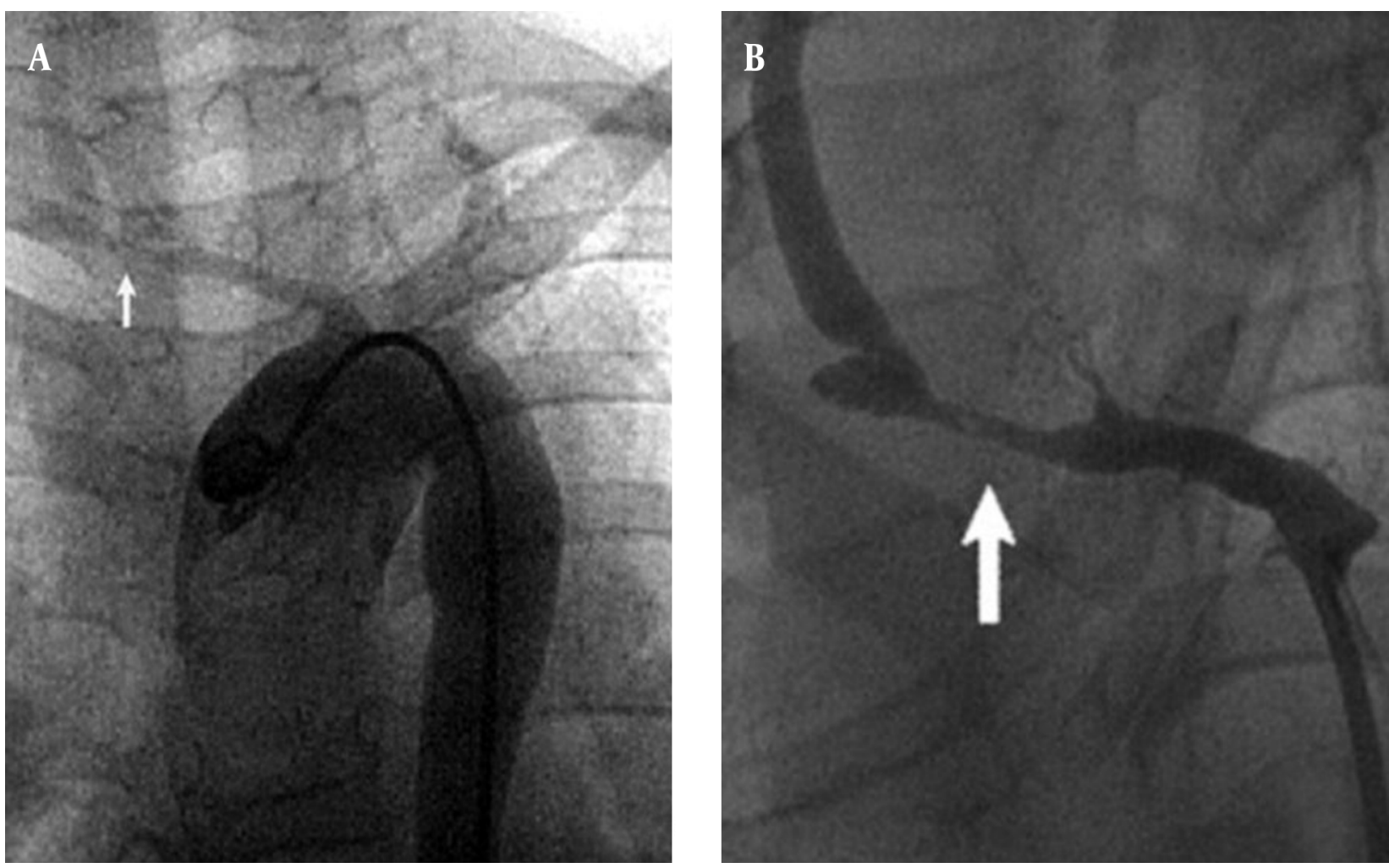

Figure 2. A, Arch Aortogram Shows Deterioration of All the Supra-Aortic Lesions; B, Transbrachial Angiogram Reveals That the Right Subclavian Artery Was Stenotic (Arrow) Proximal to the Orifice of the Vertebral Artery. Right common carotid artery was not visualized on the aortogram.

resonance angiography showed stenosis in the posterior, middle and anterior cerebral artery. Echocardiography showed fair left ventricular function, hypertrophic left ventricle with dyskinesia of the ventricular septum. She received plasmaphresis, rituximab, prednisolone, anticonvulsants (phenobarbital and phenytoin) and antihypertensive drugs.

Multislice computerized tomography showed stenosis of both carotids and subclavian arteries (Figure 1).

Due to repeated convulsions and poor general condition of the patient angiography for possible stenting the stenotic cranial arteries was done. The right innominate and subclavian artery was severely stenotic and totally occluded just proximal to the origin of the vertebral artery (Figure 2). Blood flow to the right cerebral hemisphere was supplied by the collateral channel, mainly from the vertebrobasilar system. The left common carotid and subclavian arteries were also stenotic.

Under conscious sedation anesthesia and systemic heparinization, a five-French guiding catheter was placed in the aortic arch via the femoral route and a hippocampus stent $6 \times 20 \mathrm{~mm}$ stent was deployed at the stenotic lesion of the right subclavian artery but the stenosis could not be relieved by multiple inflation of balloon (Figure 3). Subsequently, another stent (hippocampus stent $6 \times 20 \mathrm{~mm}$ ) was placed in the stenotic part, proximal to the previous stent, which markedly improved the antegrade flow of the right common carotid artery (Figure 4 ).

The symptoms disappeared immediately after the first treatment, and the patient returned to her daily life activities. Neurologic examination showed no changes during one year follow up and Doppler sonography revealed both carotid stenosis and good flow through the stent.

In cases of TA, stenting for these supra-aortic vessels, especially for the carotid lesions, has rarely been presented (4-6). Several authors have reported using subclavian stenting in cases of adult TA $(7,8)$. In our case, we think that the right vertebral artery stenting was reasonable because both carotid arteries were occluded and the right vertebral artery was functioning as the main collateral pathway to the right cerebral hemisphere, which must be preserved throughout life. To our knowledge, this is the first reported case of stenting of stenotic lesions in the supra-aortic vessels in children in Iran and also there are few reports of stenting in children in the literature. 

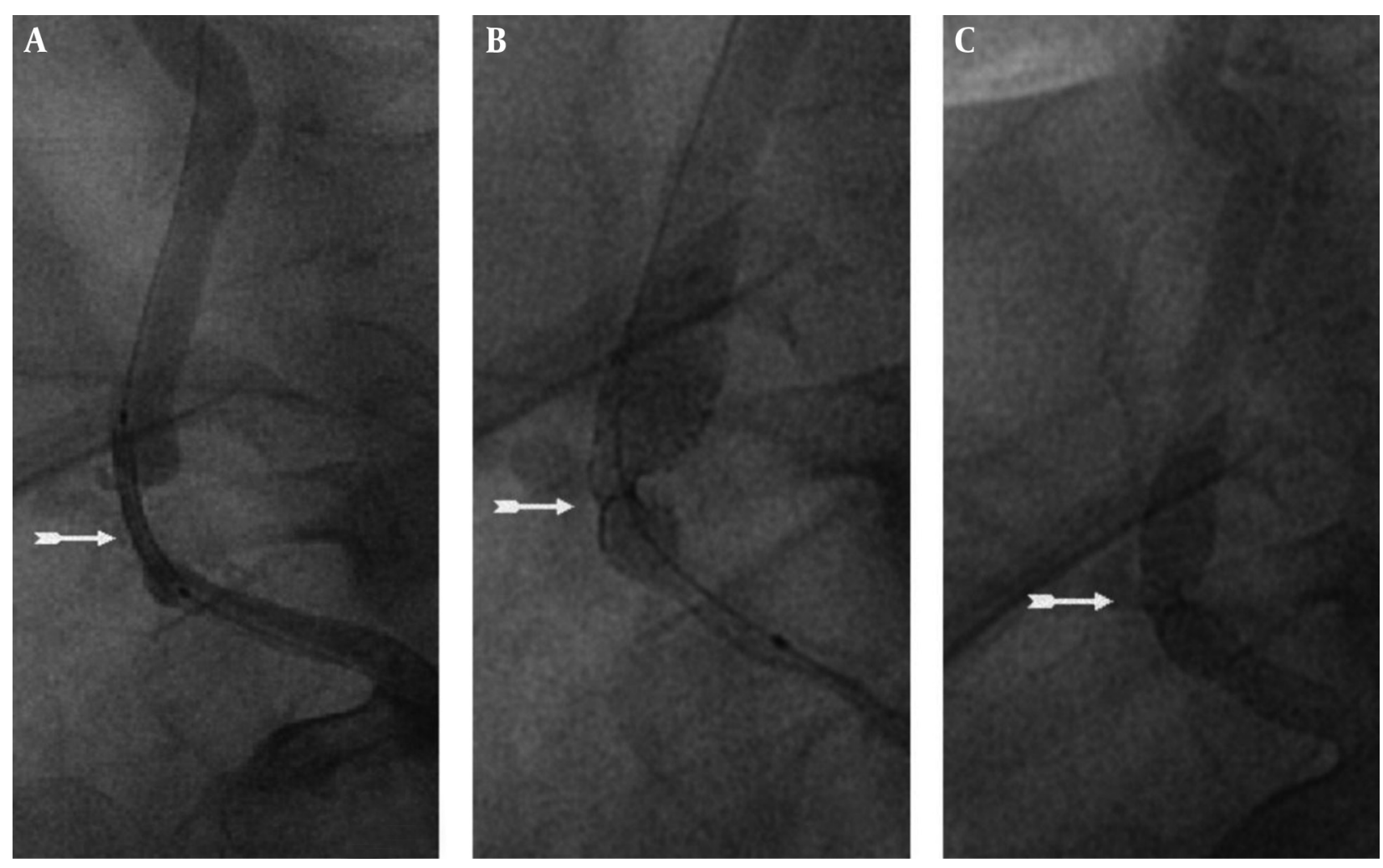

Figure 3. A and B, A Hippocampus Stent $6 \times 20 \mathrm{~mm}$ Stent Was Deployed at the Stenotic Lesion of the Right Subclavian Artery but the Stenosis Could not Be Relieved by Multiple Inflations of Balloon; C, Another Stent (Hippocampus Stent $6 \times 20 \mathrm{~mm}$ ) Was Placed in the Stenotic Part, Proximal to the Previous Stent, Which Markedly Improved the Antegrade Flow of the Right Vertebral Artery

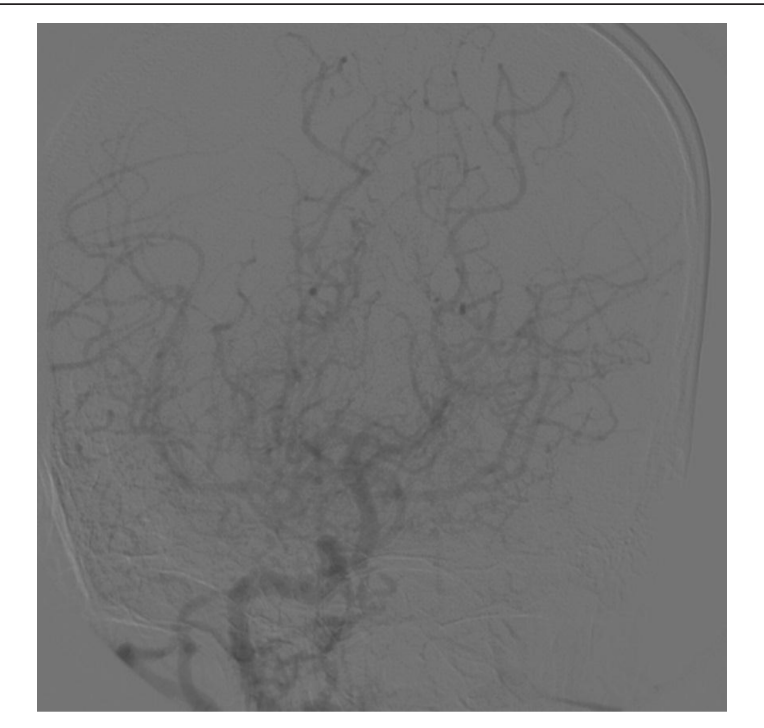

Figure 4. Final Result Showed Significant Improvement of Antegrade Flow to Right Hemisphere

\section{References}

1. Pulmonary artery disease in Takayasu's arteritis: angiographic findings. Yamada I, Shibuya H, Matsubara O, Umehara I, Makino T, Numano F, et al. AJR Am J Roentgenol. 1992;159(2):263.

2. CT angiography of Takayasu arteritis: comparison with conventional angiography. Park JH, Chung JW, Lee KW, Park YB, Han MC. J Vasc Interv Radiol. 1997;8(3):393.

3. Takayasu arteritis: evaluation with MR imaging. Yamada I, Numano F, Suzuki S. Radiology. 1993;188(1):89.

4. Ischemic stroke in Takayasu's arteritis: lesion patterns and possible mechanisms. Hwang J, Kim SJ, Bang OY, Chung CS, Lee KH, Kim DK, et al. J Clin Neurol. 2012;8(2):109.

5. Outcomes after endovascular treatment of symptomatic patients with Takayasu's arteritis. Kim HJ, Lee CS, Kim JS, Know SU, Kim JL, Park JW, et al. Interv Neuroradiol. 2011;17(2):252.

6. Eight-year follow-up of endovascular repair of a brachiocephalic trunk aneurysm due to Takayasu's arteritis. Angiletta D, Marinazzo D, Guido G, Fullone M, Pulli R, Regina G. J Vasc Surg. 2012;56(2):504.

7. Imaging findings in Takayasu's arteritis. Gotway MB, Araoz PA, Macedo TA, Stanson AW, Higgins CB, Ring EJ, et al. AJR Am J Roentgenol. 2005;184(6):1945.

8. Takayasu arteritis in children and adolescents. Brunner J, Feldman BM, Tyrrell PN, Kuemmerle-Deschner JB, Zimmerhackl LB, Gassner I, et al. Rheumatology (Oxford). 2010;49(10):1806. 